\title{
Fourier domain optical coherence tomography to assess the iridocorneal angle and correlation study in a large Caucasian population
}

José Ignacio Fernández-Vigo ${ }^{1,2^{*}}$, Julián García-Feijóo ${ }^{1}$, José María Martínez-de-la-Casa', Javier García-Bella', Pedro Arriola-Villalobos ${ }^{1}$, Cristina Fernández-Pérez ${ }^{3}$ and José Ángel Fernández-Vigo ${ }^{2,4}$

\begin{abstract}
Background: Recently, novel anatomic parameters that can be measured by optical coherence tomography (OCT), have been identified as a more objective and accurate method of defining the iridocorneal angle. The aim of the present study is to measure the iridocorneal angle by Fourier domain (FD) OCT and to identify correlations between angle measurements and subject factors in a large healthy Caucasian population.

Methods: A cross sectional study was performed in 989 left eyes of 989 healthy subjects. The iridocorneal angle measurements: trabecular-iris angle (TIA), angle opening distance $\left(\mathrm{AOD}_{500}\right)$ and trabecular-iris space area $\left(T I S A_{500}\right)$ $500 \mu \mathrm{m}$ from the scleral spur, were made using the FD-OCT RTVue ${ }^{\circledast}$. Iris thickness was also measured. Correlations were examined between angle measurements and demographic and ocular factors. The main determinants of angle width were identified by multivariate linear regression.

Results: TIA could be measured in $94 \%$ of the eyes, and $\mathrm{AOD}_{500}$ and $\mathrm{TISA}_{500}$ in $92 \%$. The means recorded were TIA $35.8 \pm 12.2$ degrees (range 1.5 to 76.1 ), AOD $_{500} 542.6 \pm 285.4 \mu \mathrm{m}$ (range 15 to 1755), and TISA $5000.195 \pm 0.104$ $\mathrm{mm}^{2}$ (range 0.02 to 0.62 ). The correlation between the temporal and nasal quadrant was $R=0.902$ for TIA. The reproducibility of measurements was excellent (intraclass correlation coefficient $>0.947$ ). Mean angle width measurements were smaller in women $(p=0.02)$. Correlation was detected between angle means and anterior chamber volume ( $A C V ; R=0.848)$, anterior chamber depth ( $A C D ; R=0.818)$, spherical error $(R=-0.619)$ and age $(R$ $=-0.487)$, while no correlation was observed with Intraocular pressure $(R=-0.052)$. ACV emerged as the main determinant of TIA $\left(R^{2}=0.705 ; p<0.001\right)$.
\end{abstract}

Conclusions: In this Caucasian population, strong correlation was detected between FD-OCT anterior angle measurements and ACV, ACD, spherical refractive error and sex, emerging the ACV as the main determinant of TIA.

Keywords: Anterior chamber, Iridocorneal angle, Glaucoma, Optical coherence tomography

\footnotetext{
* Correspondence: jfvigo@hotmail.com

'Department of Ophthalmology, Hospital Universitario Clínico San Carlos,

Instituto de Investigación sanitaria San Carlos (IdISSC), c/Profesor Martín

Lagos s/n, 28100 Madrid, Spain

${ }^{2}$ Centro Internacional de Oftalmología Avanzada, Madrid, Spain

Full list of author information is available at the end of the article
} 


\section{Background}

Anterior segment optical coherence tomography (OCT) is a recent addition to the imaging techniques available such as devices based on Scheimpflug technology or Ultrasound biomicroscopy, to measure the anterior chamber angle, or iridocorneal angle, [1-6] as a way to identify subjects with occludable angles or those at risk of angle closure. OCT has evolved from time-domain to Fourierdomain (FD) or spectral-domain systems and now offers enhanced signal-to-noise ratio, image acquisition speed and resolution $[7,8]$.

Several subject factors have been classically linked to a risk of developing primary angle-closure glaucoma [9] such as female sex, hyperopia, advanced age and a narrow anterior chamber [10-12]. More recently, several novel anatomic parameters that can be measured by OCT, including trabecular-iris angle (TIA), angle opening distance (AOD) and trabecular-iris space area (TISA), [13] have been identified as a more objective and accurate method of defining the iridocorneal angle. These new parameters allow for a more accurate assessment of the factors linked to angle closure.

Most large studies performed to date on the iridocorneal angle have examined Asian subjects [10-12, 14-16]. However, there are scarce data available for Caucasians despite differences, as some studies have demonstrated that Chinese have a narrower anterior angle than Caucasian eyes, even after correcting for anterior chamber depth $[17,18]$.

The aim of the present study was to measure anterior angle width by FD-OCT in a large population of healthy Caucasian subjects and to examine possible correlations with demographic and ocular factors. The reproducibility of the angle measurements made was also assessed.

\section{Methods}

A cross-sectional study was performed in 1006 healthy subjects consecutively recruited among patients visiting the Centro Internacional de Oftalmología Avanzada in Madrid (Spain) for a routine eye examination over the period November 1, 2012 to June 30, 2013. The study protocol adhered to the tenets of the Declaration of Helsinki and received Institutional Review Board approval from the above center. After undergoing a complete medical history and full eye examination, signed informed consent was obtained from subjects meeting the study's inclusion and exclusion criteria.

\section{Subjects}

Inclusion criteria were an age between 18 and 85 years and Caucasian ethnicity. Subjects were excluded if they had been diagnosed with an eye disease or if any eye disorder was detected in the exam such as glaucoma or a mature cataract, previous ocular surgery, a history of ocular trauma, or an ocular or iridocorneal angle abnormality. Also excluded from the study were subjects with a physical or mental condition that could hinder the examination, and subjects under treatment with any medication that could affect intraocular pressure (IOP).

\section{General examination protocol}

All participants underwent a standard examination including general medical history, visual acuity, slit-lamp anterior biomicroscopy, posterior segment ophthalmoscopy and IOP measured using a Canon TX $10^{\circ}$ pneumotonometer (Canon Inc.; Tokyo, Japan). Participants were also subjected to a Pentacam ${ }^{\circ}$ (Oculus Inc.; Wetzlar, Germany), IOL Master (Carl Zeiss, Meditec, USA) and OCT RTVue (Optovue Inc., Fremont, CA, USA) examination on the same day. The room lighting conditions for all tests were set at $7 \mathrm{EV}$, or 320 lux, using a Flashmate $\mathrm{K}-308 \mathrm{~S}^{\oplus}$ light meter (SEKONIC, Tokyo, Japan).

The eye randomly selected for all measurements was the left eye of each participant. The measurements made with the Pentacam $^{\circ}$ were anterior chamber volume $(\mathrm{ACV})$ and depth (ACD) (measured from the epithelium) and central corneal thickness (CCT). The IOL Master ${ }^{\bullet}$ was used to measure axial length (AL), corneal diameter or white-to-white distance (WTW), and pupil diameter.

\section{Fourier Domain OCT}

A Fourier domain OCT RTVue 100 with a CAM-L lens was used for the anterior angle measurements and for iris thickness. Exams were performed on the nasal and temporal quadrants (3 and 9 o'clock) under mesopic conditions with the device's software set to Angle mode. In this mode, a $3 \times 2.3 \mathrm{~mm}$ area was subjected to $32 \mathrm{~B}$ scans, each comprised of 1024 A-scans, centered at the limbus. Each B-scan lasted 0.04 seconds.

Images were obtained by a trained examiner (JIFV) with the patient sitting and looking ahead. Only images of a quality indicated by a signal strength intensity (SSI) greater than 30 were accepted. Each quadrant was scanned three times and the examiner chose the image showing the best quality and least noise.

The measurements made manually on these images were trabecular-iris angle (TIA), angle opening distance $500 \mu \mathrm{m}$ from the scleral spur $\left(\mathrm{AOD}_{500}\right)$ and trabeculariris space area $\left(\right.$ TISA $\left._{500}\right) 500 \mu \mathrm{m}$ from the scleral spur $[6,11]$. In Fig. 1, it may be seen how these measurements were made. TIA was measured by tracing a line from the angle recess to the Schwalbe's line and another line on the surface of the iris to the perpendicular point on the Schwalbe's line. $\mathrm{AOD}_{500}$ was measured as the perpendicular distance from the trabecular meshwork, $500 \mu \mathrm{m}$ anteriorly from the scleral spur to the anterior 


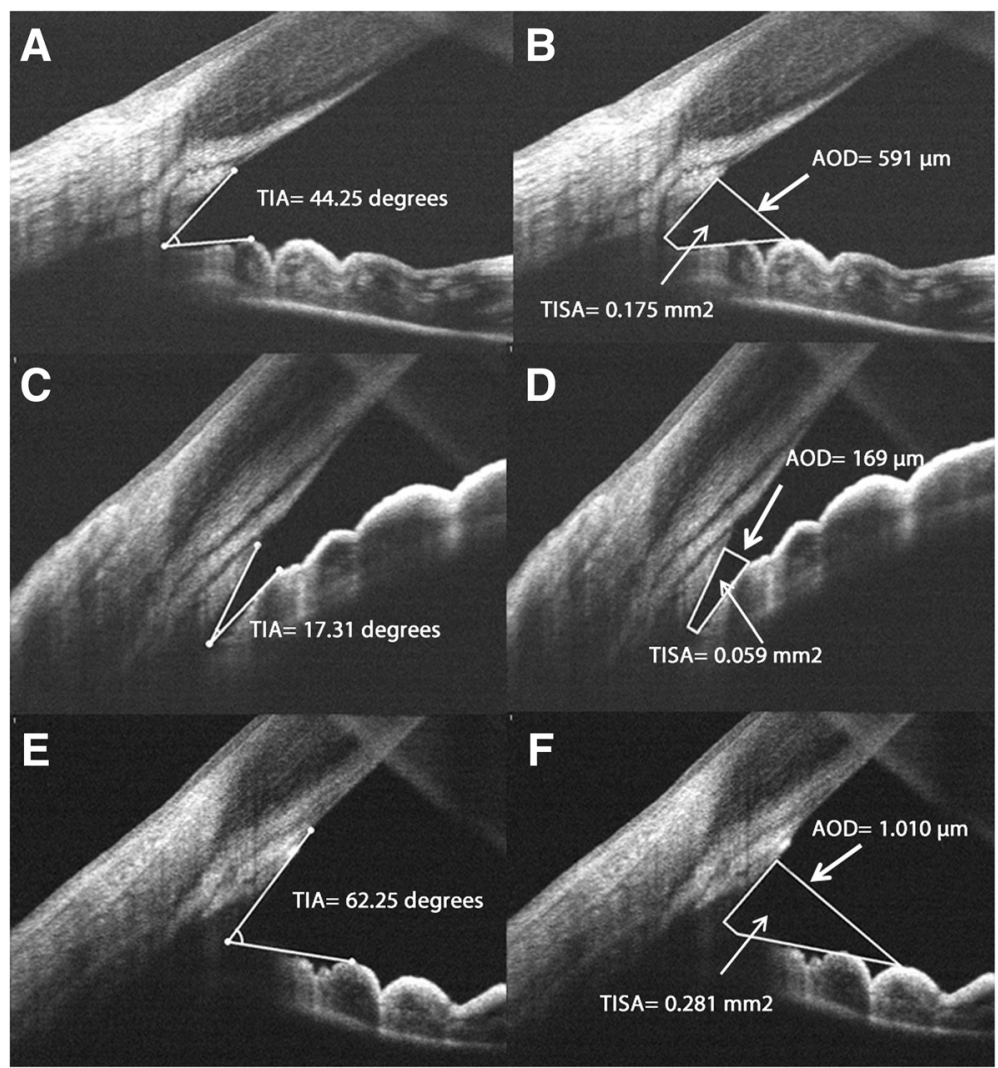

Fig. 1 Examples of iridocorneal angle measurements made by Fourier Domain optical coherence tomography images. a Trabecular-iris angle (TIA) and (b) Angle opening distance $500 \mu \mathrm{m}$ from the scleral spur $\left(\mathrm{AOD}_{500}\right)$ and trabecular-iris space area $\left(\mathrm{TISA}_{500}\right) 500 \mu \mathrm{m}$ from the scleral spur in a normal angle width. $\mathbf{c}$ and $\mathbf{d} T \mathrm{TI}, \mathrm{AOD}_{500}$ and TISA $\mathrm{A}_{500}$ measurements in a narrow angle. e and (f) TIA, $\mathrm{AOD}_{500}$ and TISA $\mathrm{A}_{500}$ measurements in a wide angle

iris surface. TISA 500 was defined as the area bounded anteriorly by the AOD, posteriorly by a line drawn from the scleral spur perpendicular to the plane of the inner scleral wall to the opposing iris, superiorly by the inner corneoscleral wall, and inferiorly by the iris surface. Using this instrument, iris thickness was also measured manually as the perpendicular distance from the trabecular meshwork $500 \mu \mathrm{m}$ anteriorly to the scleral spur $\left(\mathrm{IT}_{500}\right)$.

\section{Reproducibility}

To assess the reproducibility of angle measurements made using the RTVue ${ }^{\circ}$ OCT, measurements were made in a subset of 50 patients selected at random from our study population. To determine interobserver reproducibility, angle measurements were independently made on the images obtained in the initial exam by two observers (JIFV and JAFV). One observer (JIFV) repeated the scanning with $\mathrm{OCT}$ and the angle measurements two weeks after the first examination to determine intraobserver reproducibility. In this subset, we also compared angle measurements between the right and left eyes.

\section{Statistical analysis}

All statistical tests were performed using the software package SPSS $^{\circ}$ (Statistical Package for Social Sciences, v18.0; SPSS Inc., Chicago, IL). Quantitative data are provided as their means and standard deviations, and qualitative data as their frequency distributions. The Kolmogorov-Smirnov test was used to determine the distribution of the variables measured. Univariate correlations were established by Pearson correlation and multivariate correlations by linear regression as $R^{2}$ values. For variables showing a non-normal distribution (spherical refractive error, $\mathrm{AOD}_{500}$ and $\mathrm{TISA}_{500}$ ) the Spearman's Rho test was used. In addition a multivariate linear regression stepwise analysis calculating $R^{2}$ was performed to identify the main factors determining a greater or lesser width of the iridocorneal angle. The reliability of the FD-OCT measurements was assessed by calculating intraclass correlation coefficients (ICC) for 
interobserver and intraobserver reproducibility. Significance was set at $p<0.05$.

\section{Results}

Iridotrabecular contact was observed in 17 eyes $(1.6 \%)$ with the FD-OCT. These eyes were excluded, because they could cause secondary alterations to the angle, being finally studied a sample of 989 eyes of 989 subjects.

Mean subject age was $49.1 \pm 15.2$ years (range 18 to 84); 615 were women (62\%). Mean intraocular pressure was $15.8 \pm 3.5 \mathrm{mmHg}$ (range 6 to 25 ) and the mean spherical error was $-0.40 \pm 3.55$ diopters (range -14 to 8.25). The remaining variables examined are shown in Table 1.

TIA could be measured in 939 eyes $(94.9 \%)$ and averaged at $35.8 \pm 12.2$ degrees (range 1.5 to 76.1 ) in the temporal quadrant, and could be measured in 931 eyes $(94.1 \%)$ in the nasal quadrant and averaged $35.7 \pm 12.3$ degrees (range 2.2 to 74.8 ). Mean $\mathrm{AOD}_{500}$ was measured in 922 and 920 eyes (93.2 and $93.0 \%$ ) in the temporal and nasal quadrants respectively, being the means 542.6 $\pm 285.4 \mu \mathrm{m}$ (range 15 to 1755 ) and $541.9 \pm 284.8 \mu \mathrm{m}$ (range 19 to 1741 ) respectively. TISA ${ }_{500}$ were $0.195 \pm$ $0.103 \mathrm{~mm}^{2}$ (range 0.02 to $0.62 \mathrm{~mm}^{2}$ ) and $0.193 \pm 0.101$ $\mathrm{mm}^{2}$ (range 0.02 to $0.60 \mathrm{~mm}^{2}$ ) in the temporal and nasal quadrant respectively. $\mathrm{IT}_{500}$ was $395.5 \pm 71.7 \mu \mathrm{m}$ (range 194 to 910 ) in the temporal quadrant and $398.1 \pm 73.2$ $\mu \mathrm{m}$ (range 198 to 921) in the nasal one. All four variables were normally distributed.

The intra- and interobserver reproducibility observed for the angle measurements (TIA, $\mathrm{AOD}_{500}$ and $\mathrm{TISA}_{500}$ ) were ICC $>0.962$ and $>0.947$, respectively (Table 2 ).

The correlation between the temporal and nasal quadrant were $\mathrm{R}=0.902$ for TIA, $\mathrm{R}=0.906$ for $\mathrm{AOD}_{500}$, and $\mathrm{R}=0.915$ for $\mathrm{TISA}_{500}$ (both, $p<0.001$ ).

TIA was 4.49 degrees greater in men than in women (95\% CI 3.35 to 5.64 degrees; $p<0.001$ ), being the means 38.60 and 34.11 degrees respectively.

Table 1 Measurements made in the study population using the Pentacam and the IOL Master

\begin{tabular}{|c|c|c|c|c|c|c|}
\hline \multicolumn{7}{|c|}{ Ocular characteristics of the study subjects } \\
\hline & \multicolumn{3}{|c|}{ Pentacam ${ }^{\oplus}$} & \multicolumn{3}{|l|}{ IOL Master ${ }^{\oplus}$} \\
\hline & $\begin{array}{l}\mathrm{ACD} \\
(\mathrm{mm})\end{array}$ & $\begin{array}{l}\mathrm{CCT} \\
(\mu \mathrm{m})\end{array}$ & $\begin{array}{l}\mathrm{ACV} \\
\left(\mathrm{mm}^{3}\right)\end{array}$ & $\begin{array}{l}\text { Axial length } \\
(\mathrm{mm})\end{array}$ & $\begin{array}{l}\text { WTW } \\
(\mathrm{mm})\end{array}$ & $\begin{array}{l}\text { Pupil diameter } \\
(\mathrm{mm})\end{array}$ \\
\hline Mean & 3.35 & 550.6 & 161.8 & 23.87 & 12.11 & 4.26 \\
\hline SD & 0.43 & 31.9 & 48.0 & 1.54 & 0.41 & 0.98 \\
\hline Maximum & 4.61 & 643 & 265 & 33.61 & 13.40 & 6.45 \\
\hline Minimum & 2.16 & 474 & 67 & 20.02 & 10.90 & 2.10 \\
\hline
\end{tabular}

$A C D$ anterior chamber depth, CCT central corneal thickness, $A C V$ anterior chamber volume, WTW white-to-white or corneal diameter, $S D$ standard deviation
Table 2 Intra- and interobserver reproducibility of anterior chamber angle measurements made by Fourier Domain OCT

\begin{tabular}{|c|c|c|c|c|}
\hline $\begin{array}{l}\text { Intraobserver } \\
\text { reproducibility }\end{array}$ & Mean \pm SD & ICC & $95 \% \mathrm{Cl}$ & $P$ value \\
\hline TIA Session 1 (degrees) & $33.66 \pm 11.38$ & 0.979 & $0.969-0.986$ & $<0.001$ \\
\hline TIA Session 2 (degrees) & $33.69 \pm 10.94$ & & & \\
\hline $\mathrm{AOD}_{500}$ Session $1(\mu \mathrm{m})$ & $491.16 \pm 281.25$ & 0.991 & $0.987-0.994$ & $<0.001$ \\
\hline $\mathrm{AOD}_{500}$ Session $2(\mu \mathrm{m})$ & $492.02 \pm 280.84$ & & & \\
\hline TISA $_{500}$ Session $1\left(\mathrm{~mm}^{2}\right)$ & $0.178 \pm 0.104$ & 0.962 & $0.944-0.974$ & $<0.001$ \\
\hline TISA $_{500}$ Session $2\left(\mathrm{~mm}^{2}\right)$ & $0.181 \pm 0.112$ & & & \\
\hline $\begin{array}{l}\text { Interobserver } \\
\text { reproducibility }\end{array}$ & Mean \pm SD & ICC & $95 \% \mathrm{Cl}$ & $P$ value \\
\hline TIA Observer 1 (degrees) & $33.66 \pm 11.38$ & 0.954 & $0.933-0.969$ & $<0.001$ \\
\hline TIA Observer 2 (degrees) & $33.03 \pm 10.55$ & & & \\
\hline $\mathrm{AOD}_{500}$ Observer $1(\mu \mathrm{m})$ & $491.16 \pm 281.25$ & 0.975 & $0.964-0.983$ & $<0.001$ \\
\hline $\mathrm{AOD}_{500}$ Observer $2(\mu \mathrm{m})$ & $480.15 \pm 295.72$ & & & \\
\hline TISA $_{500}$ Observer $1\left(\mathrm{~mm}^{2}\right)$ & $0.178 \pm 0.104$ & 0.947 & $0.922-0.964$ & $<0.001$ \\
\hline TISA $_{500}$ Observer $2\left(\mathrm{~mm}^{2}\right)$ & $0.174 \pm 0.116$ & & & \\
\hline
\end{tabular}

TIA trabecular-iris angle, $A O D_{500}$ angle opening distance $500 \mu \mathrm{m}$ from the scleral spur, $T I S A_{500}$ trabecular-iris space area $500 \mu \mathrm{m}$ from the scleral spur. ICC intraclass correlation coefficient, $95 \% \mathrm{Cl}=95 \%$ confidence interval

Univariate correlation was observed between age and TIA $(\mathrm{R}=-0.487 ; p<0.001)$. Angle width measurements diminished from 18 years to $56-60$ years, and stabilized thereafter (Fig. 2). Correlation was observed in subjects $\leq 60$ years $(\mathrm{R}=-0.496 ; p<0.001)$ but not $>60$ years $(\mathrm{R}=$ $0.015 ; p<0.001)$. The linear regression model identified a change in TIA per year until the age of 60 years (B $=-0.579 ; 95 \%$ CI -0.632 to $-0.526 ; p<0.0001$ ).

Overall correlation between TIA and spherical error was $\mathrm{R}=-0.619(p<0.001)$. Mean TIA was stable over the range $<-9$ to -3 diopters, from which point it decreased until 20.31 degrees in hyperopes of $>7$ diopters (Fig. 2). For each diopter increase in spherical error from -3 diopters to positive values, angle width variation was $\mathrm{B}$ $=-2.678(95 \%$ CI -2.906 to $-2.450 ; p<0.001)$.

No correlation was observed between TIA and IOP whether all eyes were considered $(\mathrm{R}=-0.052 ; p=0.001)$ or only those with narrow angles $(\mathrm{R}=-0.112 ; p=0.045$; angle $\leq 20$ degrees, $n=101$ eyes). The factor showing greatest correlation with TIA was ACV followed by ACD $(\mathrm{R}=0.848$ and $\mathrm{R}=0.818$ respectively; $p<0.001)$. Table 3 shows the correlations observed between the angle measurements and the remaining subject factors examined. The average intra-subject right eye/left eye correlation was $\mathrm{R}=0.886(p<0.001)$ for TIA, $\mathrm{R}=0.880(p<0.001)$ for $\mathrm{AOD}_{500}$ and $\mathrm{R}=0.870(p<0.001)$ for TISA $\mathrm{T}_{500}$.

Eight variables were included in the multivariate regression model constructed to examine the effects on final TIA variability. Age and AL were excluded by the model, to give an optimal model containing the variables: ACV, ACD, sex, spherical error, $\mathrm{IT}_{500}$ and WTW 

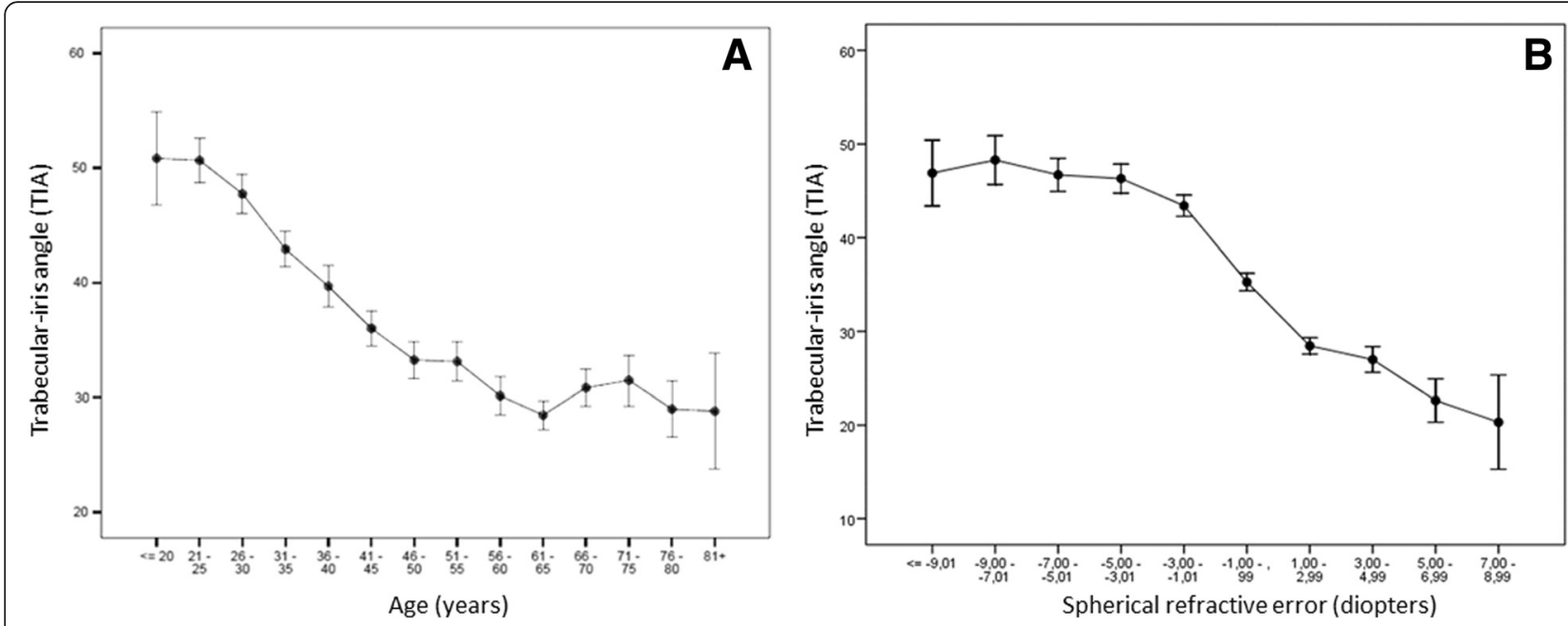

Fig. 2 a Relationship between trabecular-iris angle (TIA) and age. Angle width measurements diminished from 18 years to $56-60$ years, and stabilized thereafter. $\mathbf{b}$ Relationship between TIA and spherical refractive error. Mean trabecular-iris angle (TIA) was stable over the range <-9 to -3 diopters, point from which it was decreasing progressively toward hyperopia

that could explain $76.4 \%$ of the variation in TIA $\left(\mathrm{R}^{2}=\right.$ $0.764 ; p<0.001)$. When these variables were individually analyzed, ACV (adjusted $R^{2}=0.705$ ) emerged as the main model determinant, followed by ACD (adjusted $\mathrm{R}^{2}$ $=0.658$ ), spherical error (adjusted $R^{2}=0.256$ ), WTW (adjusted $R^{2}=0.057$ ), sex (adjusted $R^{2}=0.029$ ), and $\mathrm{IT}_{500}$ (adjusted $\mathrm{R}^{2}=0.019$ ).

\section{Discussion}

This study conducted in a large population of healthy Caucasians examines iridocorneal angle width and its correlations with several subject factors. Mean TIA in our subjects was $35.8 \pm 12.2$ degrees in the temporal quadrant,

Table 3 Correlations between the angle parameters (TIA, $\mathrm{AOD}_{500}$ and $\mathrm{TISA}_{500}$ ) and different factors of the subjects Demographic and ocular correlations with TIA, $\mathrm{AOD}_{500}$ and $\mathrm{TISA}_{500}$

\begin{tabular}{llll}
\hline Factor & TIA & AOD $_{500}$ & TISA $_{500}$ \\
\hline Age & $-0.496(p<0.001)$ & $-0.484(p<0.001)$ & $-0.454(p<0.001)$ \\
ACD & $-0.818(p<0.001)$ & $0.760(p<0.001)$ & $0.732(p<0.001)$ \\
IOP & $-0.052(p<0.001)$ & $-0.069(p=0.038)$ & $-0.076(p<0.001)$ \\
CCT & $-0.095(p<0.001)$ & $-0.092(p=0.006)$ & $-0.086(p<0.001)$ \\
ACV & $0.848(p<0.001)$ & $0.802(p<0.001)$ & $0.769(p<0.001)$ \\
Pupil size & $0.179(p<0.001)$ & $0.187(p<0.001)$ & $0.159(p<0.001)$ \\
WTW & $0.269(p<0.001)$ & $0.228(p<0.001)$ & $0.216(p<0.001)$ \\
Axial length & $0.599(p<0.001)$ & $0.570(p<0.001)$ & $0.562(p<0.001)$ \\
Spherical error & $-0.575(p<0.001)$ & $-0.545(p<0.001)$ & $-0.540(p<0.001)$ \\
Iris thickness & $0.151(p<0.001)$ & $0.188(p<0.001)$ & $0.208(p<0.001)$ \\
\hline
\end{tabular}

TIA trabecular-iris angle, $A O D_{500}$ angle opening distance $500 \mu \mathrm{m}$ from the scleral spur, $T I S A_{500}$ trabecular-iris space area $500 \mu \mathrm{m}$ from the scleral spur, $A C D$ anterior chamber depth, IOP intraocular pressure, $C C T$ central corneal thickness, $A C V$ anterior chamber volume, WTW white to white or corneal diameter and $35.7 \pm 12.3$ degrees in the nasal one. This value is fairly consistent with the values of $35.3 \pm 8.5$ degrees obtained using the RTVue OCT and $35.5 \pm 9$ degrees with the OCT Visante by Wylegala et al. [7] and of $38.3 \pm 16.3$ degrees using the slit lamp OCT by Xu et al. [10]. Mean $\mathrm{AOD}_{500}$ and TISA $\mathrm{T}_{500}$ in our study population were 542.6 $\pm 285.4 \mu \mathrm{m}$ and $541.9 \pm 284.8 \mu \mathrm{m}$; and $0.195 \pm 0.103 \mathrm{~mm}^{2}$ and $0.193 \pm 0.101 \mathrm{~mm}^{2}$ in the temporal and nasal quadrant respectively. Reported figures for these variables vary widely due to the different populations examined including those of Leung [19] $(572 \pm 275 \mu \mathrm{m}$ and $\left.0.193 \pm 102 \mathrm{~mm}^{2}\right)$, Grewal [20] $(490 \pm 220 \mu \mathrm{m}$ and $\left.0.320 \pm 0.120 \mathrm{~mm}^{2}\right)$ and Tan [21] $(486 \pm 36 \mu \mathrm{m}$ and $\left.0.173 \pm 0.014 \mathrm{~mm}^{2}\right)$, respectively.

We observed the excellent reproducibility of angle measurements made using the RTVue OCT. Similarly, good reproducibility was detected by Tan et al. [21] for the Visante OCT in Asian subjects and by Römkens et al. [22] for the CASIA OCT in Caucasians, in both cases whether the exam was performed by experts or non experts.

Among the main subject factors examined in our study, women and hyperopes showed a narrower angle width $(p<0.001)$, in agreement with the findings of other authors $[10-12,15]$.

Age in our large population of subjects examined, showed negative univariate correlation with TIA. This observation is consistent with those of other authors, [10-12] and in particular with the findings of Sun et al. [23] who noted that $\mathrm{AOD}_{500}$ also diminishes with age obtaining a similar correlation $(\mathrm{R}=-0.462 ; p<0.005)$ to the value recorded in our study $(\mathrm{R}=-0.484 ; p<0.001)$. However, the multivariate model identified age as a weak predictor of angle width, as also reported by Lavanya et al. and Foo et al. [15, 16, 24]. 
In the present sample of healthy eyes, no correlation was detected between angle width and IOP even when we only considered narrow angles, in agreement with the findings of Amerasinghe et al. [12]. In contrast, Chong et al. [25] argued that the extent of angular closure could be correlated with IOP. However, the difference detected was only a $1.3 \mathrm{mmHg}$ increase for angles showing closure in all 4 quadrants compared to no quadrant.

In the eyes examined here, strong correlation was detected between angle width and the anterior chamber variables, ACV and ACD $(\mathrm{R} \geq 0.818 ; p<0.001)$ such that narrower chambers showed a narrower angle $[10,12,15$, $18,23]$. Correlation with WTW was much weaker $(\mathrm{R}=$ $0.239 ; p<0.001)$. Iris thickness also showed weak correlation with the angle measurements though some authors have argued that this factor is a significant determinant of angle width [18, 24].

The multivariate model constructed in our study for Caucasian subjects based on six variables was able to explain $76.4 \%$ of the final variation observed in angle width. The other large model described to date by Foo et al. [16] for Asian subjects included six anterior chamber variables measured by OCT: ACV and ACD, ACW or horizontal scleral spur-to-spur distance, lens vault, iris surface area and iris thickness. This model served to explain $85.5 \%$ of the variation produced in $\mathrm{AOD}_{750}$. However, it should be mentioned that this model failed to consider factors as important as spherical error or sex.

Among the main limitations of our study was the fact that only the horizontal quadrants were studied. This was because of the poor quality of images obtained for the superior and inferior quadrants and the need to manipulate the eyelids. Another limitation was that we did not measure the lens vault despite the known contribution of this factor to angle width variation [18, 23, 24].

To the best of our knowledge, this is the first study to examine the use of FD-OCT to assess the iridocorneal angle in a large population of healthy Caucasian subjects. Our study offers reference values of angle width and demographic and ocular variable correlates for Caucasian subjects. We speculate that this technique will also help understand the anatomical changes that occur in glaucoma surgery, especially in angle surgery $[26,27]$.

\section{Conclusions}

In conclusion, our findings indicate that FD-OCT is a reliable examination technique to objectively assess the anterior chamber angle. Using this device in a large number of healthy Caucasians, strong correlation was observed between angle measurements and ACV, ACD, spherical refractive error and sex, and no correlation was detected with IOP. ACV emerged as the main determinant of anterior angle width.

\section{Ethics and consent to participate}

Signed informed consent was obtained from subjects meeting the study's inclusion and exclusion criteria. The study protocol adhered to the tenets of the Declaration of Helsinki and received Institutional Review Board approval from the Centro Internacional de Oftalmología Avanzada, Madrid (Spain).

\section{Consent to publish \\ Not applicable}

\section{Availability of data and materials}

All the data supporting our findings is contained within the manuscript.

\section{Abbreviations \\ $\mathrm{AOD}_{500}$ : angle opening distance $500 \mu \mathrm{m}$ from the scleral spur; FD- \\ OCT: Fourier domain optical coherence tomography; TIA: trabecular-iris}

angle; TISA $_{500}$ : trabecular-iris space area $500 \mu \mathrm{m}$ from the scleral spur.

Competing interests

The authors declare that they have no competing interests.

\section{Authors' contributions}

JIFV, JGF, JMC and JAFV conceived of the study, and participated in its design and coordination and helped to draft the manuscript. JIFV performed the examinations. JGB, PAV and CFP participated in the design of the study, selection of subjects and performed the statistical analysis. All authors read and approved the final manuscript.

\section{Acknowledgements}

Not applicable.

\section{Funding}

The authors declare that no funding support was received for this study.

\section{Author details}

${ }^{1}$ Department of Ophthalmology, Hospital Universitario Clínico San Carlos, Instituto de Investigación sanitaria San Carlos (IdISSC), c/Profesor Martín Lagos s/n, 28100 Madrid, Spain. ${ }^{2}$ Centro Internacional de Oftalmología Avanzada, Madrid, Spain. ${ }^{3}$ Department of Preventive Medicine, Hospital Universitario Clínico San Carlos, Instituto de Investigación sanitaria San Carlos (IdISSC), Madrid, Spain. ${ }^{4}$ Department of Ophthalmology, Universidad de Extremadura, Badajoz, Spain.

Received: 1 December 2015 Accepted: 12 April 2016

Published online: 18 April 2016

\section{References}

1. Smith SD, Singh K, Lin SC, Chen PP, Chen TC, Francis BA, et al. Evaluation of the anterior chamber angle in glaucoma: a report by the American Academy of Ophthalmology. Ophthalmology. 2013;120:1985-97.

2. Rossi GC, Scudeller L, Delfino A, Raimondi M, Pezzotta S, Maccarone M, et al. Pentacam sensitivity and specificity in detecting occludable angles. Eur J Ophthalmol. 2012;22:701-8.

3. Dinc UA, Oncel B, Gorgun E, Yalvac IS. Assessment of anterior chamber angle using Visante OCT, slit-lamp OCT, and Pentacam. Eur J Ophthalmol. 2010:20:531-7.

4. Wong HT, Lim MC, Sakata LM, Aung HT, Amerasinghe N, Friedman DS, et al. High-definition optical coherence tomography imaging of the iridocorneal angle of the eye. Arch Ophthalmol. 2009;127:256-60.

5. Cheung CY, Zheng C, Ho CL. Novel anterior-chamber angle measurements by high-definition optical coherence tomography using the Schwalbe line as the landmark. Br J Ophthalmol. 2011;95:955-9.

6. Leung CK, Weinreb RN. Anterior chamber angle imaging with optical coherence tomography. Eye. 2011;25:261-7. 
7. Wylegala E, Teper S, Nowińska AK. Anterior segment imaging: Fourier-domain optical coherence tomography versus time-domain optical coherence tomography. J Cataract Refract Surg. 2009;35:1410-4.

8. Fernández-Vigo Jl, García-Feijóo J, Martínez-de-la-Casa JM, García-Bella J, Fernández-Vigo JA. Morphometry of the trabecular meshwork in vivo in a healthy population using Fourier domain optical coherence tomography. Invest Ophthalmol Vis Sci. 2015;56:1782-8.

9. Quigley HA, Broman AT. The number of people with glaucoma worldwide in 2010 and 2020. Br J Ophthalmol. 2006;90:262-7.

10. Xu L, Cao WF, Wang YX, Chen CX, Jonas JB. Anterior chamber depth and chamber angle and their associations with ocular and general parameters: The Beijing Eye Study. Am J Ophthalmol. 2008;145:929-36.

11. Friedman DS, Gazzard G, Min CB, Broman AT, Quigley H, Tielsch J, et al. Age and sex variation in angle findings among normal Chinese subjects: a comparison of UBM, Scheimpflug, and gonioscopic assessment of the anterior chamber angle. J Glaucoma. 2008;17:5-10.

12. Amerasinghe $\mathrm{N}$, Foster PJ, Yin Wong T, Htoon HM, He M, Shen SY, et al. Variation of Angle Parameters in Asians: An Anterior Segment Optical Coherence Tomography Study in a Population of Singapore Malays. Invest Ophthalmol Vis Sci. 2009:50:2626-31.

13. Radhakrishnan S, Goldsmith J, Huang D, Westphal V, Dueker DK, Rollins AM, et al. Comparison of coherence tomography and ultrasound biomicroscopy for detection of narrow anterior chamber angles. Arch Ophthalmol. 2005:123:1053-9.

14. Nolan WP, See JL, Chew PT, Friedman DS, Smith SD, Radhakrishnan S, et al. Detection of primary angle closure using anterior segment optical coherence tomography in Asian eyes. Ophthalmology. 2007;114:33-9.

15. Lavanya R, Wong TY, Friedman DS, Aung HT, Alfred T, Gao H, et al. Determinants of angle closure in elderly Singaporeans. Arch Ophthalmol. 2008;126:686-91.

16. Foo LL, Nongpiur ME, Allen JC, Perera SA, Friedman DS, He M, et al. Determinants of angle width in Chinese Singaporeans. Ophthalmology. 2012:119:278-82.

17. Leung CK, Palmiero PM, Weinreb RN, Li H, Sbeity Z, Dorairaj S, et al. Comparisons of anterior segment biometry between Chinese and Caucasians using anterior segment optical coherence tomography. Br J Ophthalmol. 2010:94:1184-9.

18. Wang YE, Li Y, Wang D, He M, Lin S. Comparison of factors associated with occludable angle between American Caucasians and ethnic Chinese. Invest Ophthalmol Vis Sci. 2013;54:7717-23.

19. Leung CKS, Li H, Weinreb RN, Liu J, Cheung CY, Lai RY, et al. Anterior Chamber Angle Measurement with Anterior Segment Optical Coherence Tomography: A Comparison between Slit Lamp OCT and Visante OCT. Invest Ophthalmol Vis Sci. 2008:49:3469-74.

20. Grewal DS, Brar GS, Jain R, Grewal SP. Comparison of Scheimpflug imaging and spectral domain anterior segment optical coherence tomography for detection of narrow anterior chamber angles. Eye. 2011;25:603-11.

21. Tan AN, Sauren LD, de Brabander J, Berendschot TT, Passos VL, Webers CA et al. Reproducibility of anterior chamber angle measurements with anterior segment optical coherence tomography. Invest Ophthalmol Vis Sci. 2011;52:2095-9.

22. Römkens $H C$, Beckers $H J$, Frusch $M$, Berendschot $T$, de Brabander J Webers CA. Reproducibility of anterior chamber angle analyses with the swept-source optical coherence tomography in young, healthy Caucasians. Invest Ophthalmol Vis Sci. 2014:55:3999-4004.

23. Sun JH, Sung KR, Yun SC, Cheon MH, Tchah HW, Kim MJ, et al. Factors associated with anterior chamber narrowing with age: an optical coherence tomography study. Invest Ophthalmol Vis Sci. 2012;53(6):2607-10.

24. Nongpiur ME, Gong T, Lee HK, Perera SA, Cheng L, Foo LL. Subgrouping of Primary Angle-Closure Suspects Based on Anterior Segment Optical Coherence Tomography Parameters. Ophthalmology. 2013;120(12):2525-31.

25. Chong RS, Sakata LM, Narayanaswamy AK, Ho SW, He M, Baskaran M, et al. Relationship between intraocular pressure and angle configuration: an anterior segment OCT study. Invest Ophthalmol Vis Sci. 2013;54:1650-5.

26. Bussel II, Kaplowitz K, Schuman JS, Loewen NA, Trabectome Study Group. Outcomes of ab interno trabeculectomy with the trabectome by degree of angle opening. Br J Ophthalmol. 2015;99:914-9.

27. García-Feijoo J, Rau M, Grisanti S, Grisanti S, Höh H, Erb C, et al. Supraciliary Micro-stent Implantation for Open-Angle Glaucoma Failing Topical Therapy: 1-Year Results of a Multicenter Study. Am J Ophthalmol. 2015;159:1075-81.

\section{Submit your next manuscript to BioMed Central and we will help you at every step:}

- We accept pre-submission inquiries

- Our selector tool helps you to find the most relevant journal

- We provide round the clock customer support

- Convenient online submission

- Thorough peer review

- Inclusion in PubMed and all major indexing services

- Maximum visibility for your research

Submit your manuscript at www.biomedcentral.com/submit
Biomed Central 